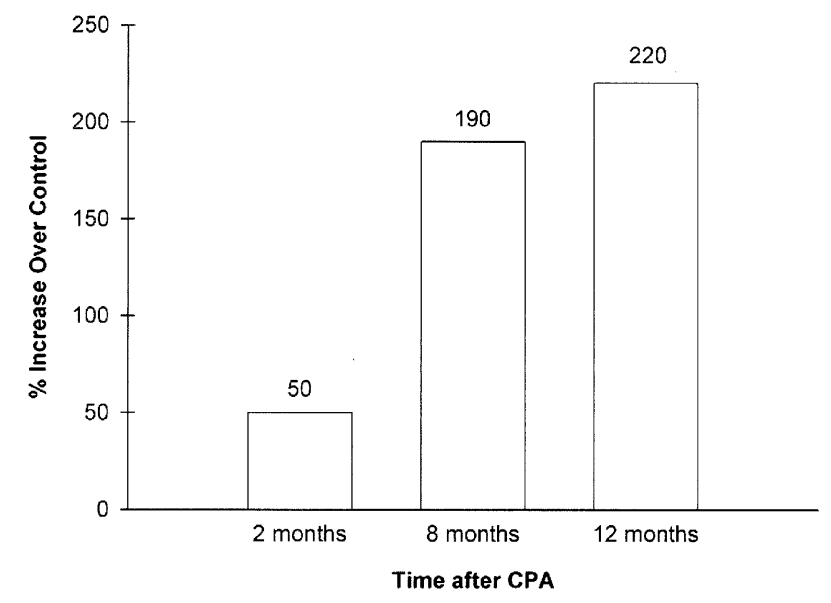

Figure 1. VEGF mRNA expression for CPA (right) versus control (left) lung. Each bar represents percentage increase of mRNA expression in CPA lung relative to control lung.

after $\mathrm{CPA}^{3}$ This study provides the first corroboration of this finding of increased VEGF protein expression by demonstrating increased VEGF mRNA expression in a rat model of PAVMs after CPA. In addition, we previously demonstrated that the number of pulmonary blood vessels demonstrate a time-dependent increase after CPA. ${ }^{2}$ This study also suggests a possible role for VEGF in this phenomenon by demonstrating a similar time-dependent increase in VEGF mRNA after CPA. Although the exact role of VEGF has not been established by this preliminary study, these findings further support its importance in the development of PAVMs after CPA.

\section{References}

1. Duncan BW, Kneebone JM, Chi EY, Hraska V, Isik FF, Rosenthal GL, et al. A detailed histologic analysis of pulmonary arteriovenous malformations in children with cyanotic congenital heart disease. J Thorac Cardiovasc Surg. 1999;117:931-8.

2. Starnes SL, Duncan BW, Kneebone JM, Fraga CH, States S, Rosenthal GL, et al. Pulmonary microvessel density is a marker of angiogenesis in children after cavopulmonary anastomosis. J Thorac Cardiovasc Surg. 2000;120:902-8.

3. Starnes SL, Duncan BW, Kneebone JM, Rosenthal GL, Patterson K, Fraga $\mathrm{CH}$, et al. Angiogenic proteins in the lungs of children after cavopulmonary anastomosis. J Thorac Cardiovasc Surg. 2001;122:51823.

4. Starnes SL, Duncan BW, Fraga CH, Desai SY, Jones TK, Mathur SK, et al. Rat model of pulmonary arteriovenous malformations after right superior cavopulmonary anastomosis. Am J Physiol Heart Circ Physiol. 2002;283:H2151-6.

5. Duncan BW, Desai S. Pulmonary arteriovenous malformations after cavopulmonary anastomosis. Ann Thorac Surg. 2003;76:1759-66.

\title{
A simple surgical technique for interventional transcatheter completion of the total cavopulmonary connection
}

Igor E. Konstantinov, MD, PhD, ${ }^{a}$ Lee N. Benson, MD, FRCPC, ${ }^{\text {b }}$ Christopher A. Caldarone, MD, ${ }^{a} \mathrm{Jia} L \mathrm{Li}, \mathrm{MD}, \mathrm{PhD},{ }^{\mathrm{b}}$ Mikiko Shimizu, MD, ${ }^{\mathrm{b}}$ John G. Coles, MD, FRCSC, ${ }^{\text {a }}$ Glen S. Van Arsdell, MD, FRCSC, ${ }^{\mathrm{a}}$ and

William G. Williams, MD, FRCSC, ${ }^{a}$ Toronto, Ontario, Canada

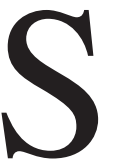

ince the initial description of interventional completion of total cavopulmonary connection (TCPC), ${ }^{1}$ few surgical maneuvers to prepare the heart for subsequent transcatheter univentricular repair have been reported., ${ }^{2,3}$ Herein, we describe a simple technique that permits surgical preparation on the beating heart.

\footnotetext{
From the Divisions of Cardiovascular Surgery and Cardiology, ${ }^{\mathrm{b}}$ Hospital for Sick Children, Toronto, Ontario, Canada.

Received for publication April 8, 2004; revisions requested April 14, 2004; accepted for publication April 20, 2004.

Address for reprints: Igor E. Konstantinov, MD, Division of Cardiovascular Surgery, Hospital for Sick Children, 555 University Ave, Toronto, Ontario, M5G 1X8 Canada (E-mail: igorkonst@hotmail.com).

J Thorac Cardiovasc Surg 2005;129:210-2

$0022-5223 / \$ 30.00$

Copyright $\odot 2005$ by The American Association for Thoracic Surgery

doi:10.1016/j.jtcvs.2004.04.011
}

\section{Technique}

The present technique evolved during experimentation in a porcine model. After approval by the Institutional Animal Care and Use Committee of the Research Institute in the Hospital for Sick Children, 4 Yorkshire pigs weighing 15, 20, 25, and $30 \mathrm{~kg}$ underwent a 2-staged procedure as described below. Superior vena cava (SVC) and inferior vena cava (IVC) were encircled with silk tapes in the first 3 animals to provide support for the covered stent (NuMed Inc, Hopkinton, NY). These support tapes were replaced with external stents (CP stent 8219, NuMed Inc) in the last animal.

Stage 1: Surgical preparation. Standard premedication, anesthesia induction, endotracheal intubation, muscle relaxation, and ventilation were achieved. Anesthesia was maintained with $1.5 \%$ to $2 \%$ isoflurane. The heart was exposed through a midline sternotomy. Heparin (300 IU/kg) was administered intravenously, and bicaval cannulation for cardiopulmonary bypass (CPB) was achieved. After institution of CPB, the caval veins were occluded by tourniquets, the right atrium (RA) was crossclamped below the sinus node, and the SVC was divided (Figure 1, $A$ and $B$ ). A bidirectional cavopulmonary shunt was performed with the heart 


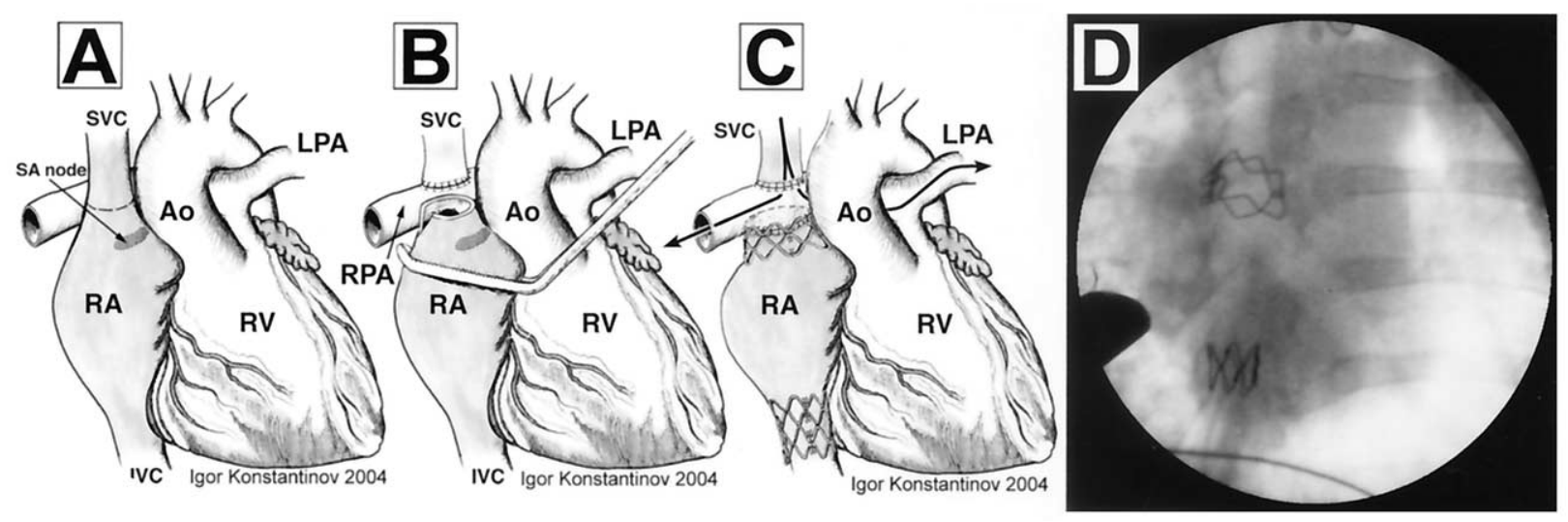

Figure 1. Stage 1: surgical preparation. The superior vena cava (SVC) is mobilized and transected high above the sinoatrial (SA) node (A). The SVC is anastomosed to the right pulmonary artery (RPA). With the right atrium (RA) crossclamped below the SA node, the proximal end of the SVC is enlarged (B) and anastomosed blindly to unopened RPA (C). After establishing of the bidirectional cavopulmonary shunt, 2 stents are placed around the atriocaval junctions (C). Both stents are visible on fluoroscopy (D). Ao, Aorta; LPA, left pulmonary artery; RV, right ventricle.

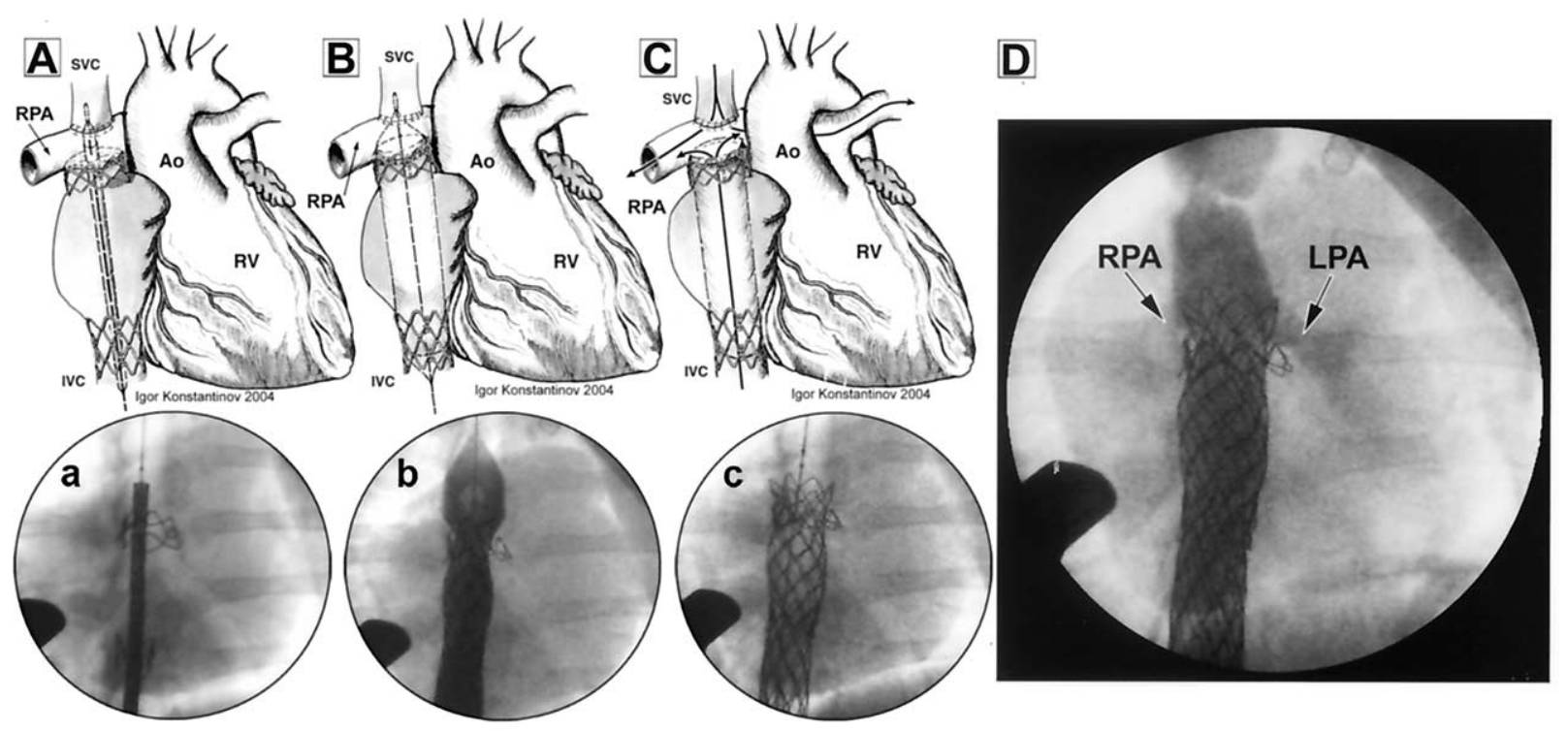

Figure 2. Stage 2: interventional catheter completion. The catheter is introduced into the right atrium (RA), and the right pulmonary artery (RPA) is perforated (A). A covered stent graft is expanded against the superior and inferior stents (B). The inferior vena caval (IVC) blood flow is diverted to the pulmonary circulation by means of the covered stent graft (C). Contrast is injected into the completed total cavopulmonary connection (D). Ao, Aorta; LPA, left pulmonary artery; $R V$, right ventricle; $S V C$, superior vena cava.

beating. The cardiac end of the divided SVC was anastomosed to the unopened inferior wall of the right pulmonary artery (RPA; Figure 1, $B$ and $C$ ). A 16-mm-long stent (CP stent 8219, NuMed Inc) was opened longitudinally and placed around the cardiac stem of the SVC, and a similar 22-mm-long stent was placed around the IVC above the diaphragm (Figure 1, $C$ ). The approximated edges of each stent were secured together with 2-0 Prolene sutures (Ethicon, Inc, Somerville, NJ) to re-establish circular continuity (Figure 1, $C$ and $D$ ). CPB was weaned and discontinued.

Stage 2: Interventional catheter completion. Venous access was established percutaneously through the right femoral vein. A long 8F dilator (Mullins, Cook Inc, Bloomington, Ind) was guided through the RA into the stent-banded SVC stump. A straight 18-gauge transseptal needle (Cook Inc) perforated the anastomosis into the RPA. With the needle as a guide, the dilator was advanced into the RPA. The needle was then removed, and an extra-stiff interventional wire (Amplatz type, 0.035 in, Cook Inc) was positioned into the SVC. The dilator was removed, and a $14 \mathrm{~F}$ Mullins sheath (Cook Inc) was guided into the RPA (Figure 2, A). Through the long sheath, a covered 50-mm-long cavopulmonary stent (NuMed) was guided to straddle the SVC and IVC external stents and dilated (Figure 2, B). Balloon dilatation of the covered 
stent against the previously placed external stents was performed (Figure 2,B). The TCPC was established on balloon deflation and removal (Figure 2, $C$ ). Angiography demonstrated a patent TCPC (Figure 2,D).

\section{Results}

All 4 animals survived and maintained normal sinus rhythm throughout both stages of the procedure. Successful TCPC was established in all animals without bleeding, stent displacement, or perforation.

\section{Discussion}

Sidiropoulos and colleagues ${ }^{2}$ reported a technique that combined a bidirectional cavopulmonary shunt and an intra-atrial lateral wall polytetrafluoroethylene baffle (Gore-Tex; W. L. Gore \& Associates, Inc, Flagstaff, Ariz) with multiple perforations to allow blood flow from the IVC into the atrium. The cardiac end of the SVC was subtotally banded. This method requires aortic crossclamping and IVC blood flow through the small perforations that might close while the patient awaits TCPC completion. Klima and colleagues ${ }^{3}$ reported experimental techniques, in which the unidirectional cavopulmonary shunt to the RPA was established off pump by means of a polytetrafluoroethylene graft and connected to the IVC through a self-expanding stent graft. Cheatham and associates ${ }^{4}$ and Murphy and coworkers ${ }^{5}$ have recently reported a similar approach by using a hemi-Fontan connection.

This new technique has the following advantages compared with previously described methods. It does not require cardiac arrest. A bidirectional cavopulmonary shunt can be established with the use of CPB but, if desired, without $\mathrm{CPB}$ aided by a temporary SVC-to-RA shunt. A fenestration of the intracardiac covered stent can be performed if needed. The stent graft could be dilated by using a catheter later in life to accommodate a patient's growth. The external caval stents are visible on fluoroscopy, providing an excellent marker for later percutaneous TCPC completion, as well as a buttress for the covered graft to expand within, allowing for a more reliable hemostatic seal. Finally, the IVC stent allows placement of the covered graft away from the hepatic veins.

\section{References}

1. Hausdorf G, Schneider M, Konertz W. Surgical preconditioning and completion of total cavopulmonary connection by interventional cardiac catheterization: a new concept. Heart. 1996;75:403-9.

2. Sidiropoulos A, Ritter J, Schneider M, Konertz W. Fontan modification for subsequent non-surgical Fontan completion. Eur J Cardiothorac Surg. 1998;13:509-12.

3. Klima U, Peters T, Peuster M, Hausdorf G, Haverich A. A novel technique for establishing total cavopulmonary connection: from surgical preconditioning to interventional completion. J Thorac Cardiovasc Surg. 2000;120:1007-9.

4. Cheatham JP, Galantowicz M, Torres W, Tower AJ, Hill SL, Kleinman $\mathrm{CS}$, et al. The use of custom-made covered NuMed CP stents in the treatment of congenital heart disease [abstract]. Catheter Cardiovasc Interv. 2002;57:100.

5. Murphy JD, Murdison KA, Nehgme RA, Pizzaro C, Norwood WI. Catheter facilitated completion of Fontan procedure [abstract]. Circulation. 2003;108(suppl IV):704.

\title{
Transsternal transpericardial approach for acute descending necrotizing mediastinitis
}

\author{
Franco Stella, MD, PhD, and Francesco Petrella, MD, Bologna, Italy
}

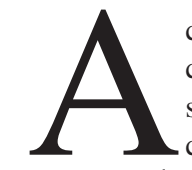

cute mediastinitis is a severe infection of mediastinal connective tissue between the 2 pleural cavities and surrounding median thoracic structures. It is usually caused by esophageal perforations or poststernotomy infections. ${ }^{1}$ Descending necrotizing mediastinitis (DNM) is one of

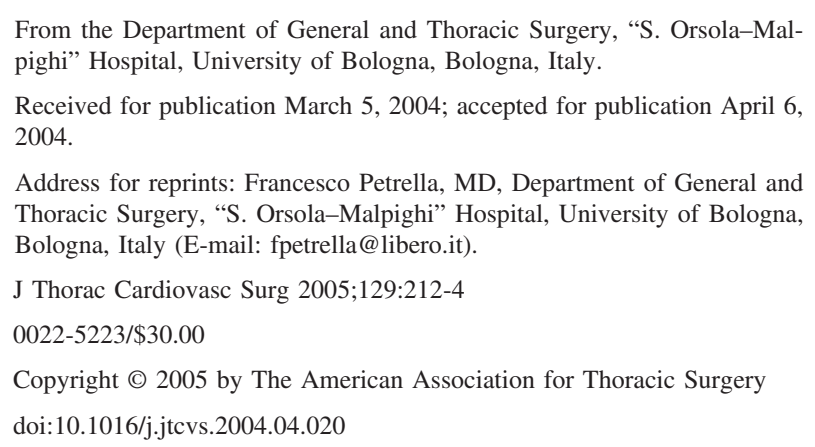

the most dangerous mediastinal infections and is caused by odontogenic or cervicofascial infections or cervical trauma. Infection descends along the deep cervical fascial space, causing cellulitis, necrosis, and abscess formation in the mediastinum, leading to sepsis. Hasegawa and coworkers ${ }^{2}$ proposed classifying DNM into 3 groups on the basis of infection extension: type I, infection localized in the upper mediastinum above the tracheal bifurcation and not always requiring aggressive mediastinal drainage; type IIA, infection extending to the lower anterior mediastinum; and type IIB, infection extending to the anterior and lower posterior mediastinum and demanding complete mediastinal drainage.

Only small series of DNM have been reported in recent literature, with mortality rates of between $25 \%$ and $40 \%$ in different series. $^{3}$ Toilette, debridement, drainage of infected fluid collections, and necrotic tissue exeresis are the surgical gold standard therapy, but the best surgical approach for this operation remains controversial.

We report a case of acute DNM after left parapharyngeal abscess that was treated through a transsternal transpericardial 